\title{
Regularização de imóveis em Santa Maria
}

Área Temática Tecnologia e Produção

\author{
Carlos José Antônio Kümmel Félix ${ }^{1}$ \\ Thiago Palharini de Lima² \\ Cristiane G. Franz ${ }^{3}$ \\ Marina Maciel ${ }^{4}$ \\ Vanessa Cirolini Lucchese ${ }^{5}$
}

\begin{abstract}
RESUMO
Os cidadãos brasileiros almejam ter sua casa própria; porém, devido à burocracia envolvida e aos custos elevados, acabam apelando para a informalidade. Assim, uma grande quantidade de mão de obra informal atua no ramo da construção civil, principalmente em habitações unifamiliares, o que resulta em inúmeras edificações ilegais. Analisando essa situação, alguns alunos da Engenharia Civil da Universidade Federal de Santa Maria criaram uma empresa júnior (associação sem fins lucrativos formada apenas por universitários voluntários) para desenvolver o projeto de Regularização Imobiliária de Baixo Custo. A proposta de trabalho é, com dados do governo municipal, mapear a localização dos cidadãos que não possuem a casa regularizada e colocar as pessoas que constroem suas moradias de forma irregular dentro da lei, garantindo o habita-se e a escritura para o dono do imóvel, além da atualização da matrícula do terreno. Com a empresa júnior, vários colaboradores ajudam a executar todas as etapas do projeto, garantindo sua continuidade.
\end{abstract}

PALAVRAS-CHAVE: Engenharia Civil. Regularização Imobiliária. Empreendedorismo.

\section{Contexto da Ação}

A moradia é uma necessidade básica do ser humano e objeto de desejo de todas as classes sociais. Porém, para que esse sonho se torne realidade, é comum que seu projeto e execução ocorram de forma imprópria e através de mão de obra informal. Isso resulta em habitações inseguras e que não podem ser regularizadas, o que acarreta pagamento de altos impostos, impossibilidade de venda da residência e até sua desapropriação.

\footnotetext{
1 Professor do Curso de Engenharia Civil, Universidade Federal de Santa Maria. E-mail: cjafelix@yahoo.com.br.

${ }^{2}$ Aluno da Engenharia Civil. Apresentador do projeto. Universidade Federal de Santa Maria.

${ }^{3}$ Aluna da Engenharia Civil, Universidade Federal de Santa Maria.

${ }_{5}^{4}$ Aluna da Engenharia Civil, Universidade Federal de Santa Maria.

${ }^{5}$ Aluna da Engenharia Civil, Universidade Federal de Santa Maria.
} 
Segundo a revista Veja de São Paulo (ANTUNES et al., 2013), cerca de 70\% dos imóveis não residenciais paulistanos são ilegais. Essas construções funcionam sem licença, têm reformas clandestinas ou ocupam uma área maior que a permitida, o que acontece porque os indivíduos responsáveis por esses locais, em geral, não têm condições de pagar um profissional da área de Engenharia ou Arquitetura para projetar e executar seus imóveis dentro da lei. Portanto, a situação das habitações brasileiras é crítica e há grande necessidade de programas que visem à redução desse problema.

Pensando nisso, o projeto da Regularização Imobiliária surgiu para atender a essa demanda da sociedade, que, sem um programa específico de consultoria, levantamento e encaminhamento do processo legal, não tem como arcar com os custos da legalização dos imóveis. Busca-se prestar serviços de qualidade e de custo acessível às classes menos favorecidas da sociedade e colaborar com o poder público para o levantamento de imóveis irregulares.

\section{Justificativa}

A importância social do tema é apresentar uma alternativa de baixo custo e qualidade ao perfil da sociedade santa-mariense. Os cidadãos brasileiros almejam ter sua casa própria; contudo, devido à burocracia e aos custos existentes nesse contexto, apelam para a informalidade. Segundo a Prefeitura de Santa Maria (SANTA MARIA, 2013), no município o IPTU de imóveis pago por essas pessoas chega a ser o dobro, dificultando a sua ascensão social.

Por meio do projeto, os acadêmicos ampliam competências ligadas ao exercício da profissão e aptidões práticas necessárias à vida profissional, inclusive adquirem conhecimento de mercado e desenvolvem o espírito de empreendedorismo. 0 projeto ainda oferece a oportunidade de se trabalhar com diferentes "vitrines" sociais, desenvolvendo, em todos os envolvidos, uma visão social dos problemas ligados à Engenharia, que, em geral, é uma área vista pelo público apenas como técnica e pouco humana. 


\section{Objetivo Geral}

É objetivo geral regularizar imóveis da população de baixa renda e formar profissionais aptos a trabalhar com isso.

\section{$4 \quad$ Objetivos Específicos}

São objetivos específicos contribuir para a formação e o crescimento profissional e humano de acadêmicos da Engenharia Civil, através da prestação de serviços dentro de suas respectivas áreas de atuação; promover uma maior integração entre a sociedade e as instituições de ensino, colaborando para o desenvolvimento de ambas; proporcionar aos membros do projeto aplicações práticas dos conhecimentos adquiridos durante o curso; valorizar e reconhecer os discentes, os docentes e a UFSM no âmbito social; incentivar o empreendedorismo; prestar serviços relevantes para o desenvolvimento da sociedade; e disseminar a ideia da sustentabilidade dentro do ambiente acadêmico.

\section{Detalhamentos da Ação - População Beneficiada}

Nas cidades brasileiras, no intuito de economizar nos impostos, os proprietários entregam a construção de suas casas para profissionais ilegais. Dessa maneira, o mercado para a regularização está em constante ascensão, pois a população continua construindo fora do Código de Obras; não por má fé, mas por falta de informações ou de recursos. Na Base Júnior, o serviço é focado em legalização de imóveis, pois há uma alta demanda santa-mariense neste ponto específico.

Desse modo, junto com a Prefeitura Municipal de Santa Maria, o projeto busca atender esta demanda da sociedade, que não possui um programa específico de consultoria, levantamento, registro físico e encaminhamento do processo legal, além de não ter como arcar com os custos da legalização dos imóveis. Neste prisma, a empresa júnior realiza serviços de qualidade e de custo acessível às classes menos favorecidas da sociedade e colabora com o poder público para o levantamento de imóveis irregulares. 
0 projeto se desenvolve em etapas, iniciando com a venda e divulgação do serviço, que são feitas a partir do contato com os líderes comunitários das regiões visitadas previamente. A verificação da aceitação ou não do produto é feita por telefone. Existe uma equipe interna responsável pela venda do serviço, que também vai até as localidades para promovê-lo. Depois disso, o atendimento ao cliente é feito por telefone e também por e-mail. Na venda, os membros esclarecem aos clientes quais são as vantagens do serviço para a sua vida, e então é mostrado um orçamento detalhado, com base nas horas de desenvolvimento e nos custos. Após a venda e a assinatura do contrato, três membros são designados para fazer o serviço e orientar o cliente sobre o que deve legalmente ser feito. Cada grupo leva prancheta, folhas, câmera fotográfica, caneta/lapiseira e trena para a realização das medições do local.

A partir disso, as plantas exigidas pela prefeitura são executadas na sede, conquistada através da parceria com o laboratório Pro+E, do Centro de Tecnologia, usando o software AutoCAD, que já está instalado nos computadores da universidade. Juntamente, é feito o pedido de informações urbanísticas, a fim de montar o laudo técnico. As plantas são plotadas, e a entrega é feita, sempre, pessoalmente ao cliente. 0 prazo de entrega será um consenso entre as necessidades do cliente e a disponibilidade da equipe, não devendo esse prazo ser ultrapassado. Em média, ele é de 30 dias.

\section{Análise e Discussão}

A Figura 1 mostra dados fornecidos pela prefeitura. Entretanto, acredita-se que o mercado seja ainda maior, uma vez que cada cliente compra o serviço uma vez apenas e a empresa tem condições de realizar a regularização de três construções por mês. Como resultado, a estimativa é de que haja trabalho disponível para 50 anos, caso a Base Júnior seja a única a executar este serviço. Ainda assim, esse resultado não está levando em conta o crescimento inevitável de moradias nessa situação; portanto, esse número é ainda maior. 


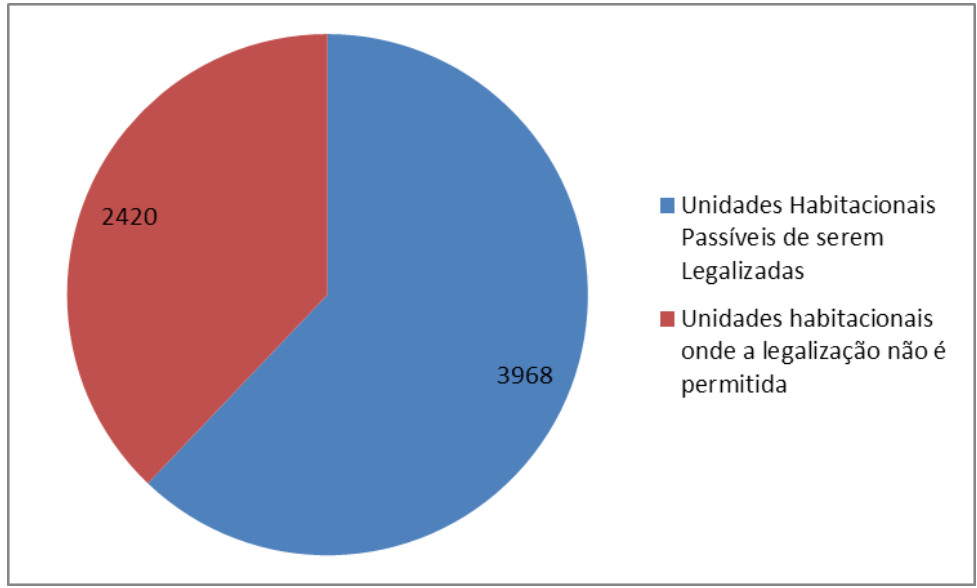

Figura 1: Unidades habitacionais irregulares passíveis de regulamentação Fonte: Santa Maria (2013)

No momento, o projeto conta com dois serviços de regularização imobiliária em andamento. Até agora, em um deles, que é a regularização de uma cabana, foram refeitas todas as plantas: de situação (situação do terreno em relação à rua), localização (do imóvel em relação ao terreno), cortes longitudinal e transversal, e as plantas baixas do primeiro e segundo piso. Na outra casa, localizada no bairro Chácara das Flores, que está em sua fase inicial, estão sendo feitas as medições do imóvel, uma vez que todas as plantas serão realizadas do zero. Para realizar esses serviços, toda a equipe recebeu treinamentos, incluindo aulas do software AutoCad. Outra atividade da área de projetos é a estruturação de um manual com o passo a passo detalhado do trabalho prestado, constando nesse documento tudo o que é preciso para que seja feita a regularização do imóvel, desde a sua fase inicial, passando por toda a padronização de plantas, até o final do processo, quando a certidão de habite-se é entregue ao proprietário. 0 objetivo é perpetuar o projeto e melhorar cada vez mais a forma de executá-lo.

Como resultado, o projeto ficou classificado entre os 300 Melhores Negócios do Brasil Prêmio Santander de Empreendedorismo de 2012 e em quinto no VIII Congresso 
Internacional de Engenharia Civil, realizado no Peru. Esse resultado despertou o interesse dos professores do curso de Engenharia Civil, dos quais se espera que se inspirem e apliquem esse conceito em diferentes áreas de abrangência da profissão, dando oportunidades de crescimento a um maior número de alunos.

\section{Agradecimentos}

A Base Júnior é grata ao Pro+E por ceder o espaço, pois, sem esse apoio, a empresa júnior teria seu crescimento muito limitado; à empresa de consultoria Dendrus, que, desde o início até hoje, auxilia em todas as etapas de estruturação e planejamento da empresa; à UFSM e ao Centro de Tecnologia; ao professor Carlos José Antônio Kümmel Félix, coordenador do curso de Engenharia Civil da UFSM, grande apoiador do projeto; e aos professores Nilza Zampieri e Luiz Antônio Righi.

\section{Referências}

ANTUNES, C. et al. Cerca de 70\% dos imóveis não residenciais paulistanos são ilegais. [2013]. Disponível em: <http://vejasp.abril.com.br/revista/edicao2103/cercade-70-dos-imoveis-nao-residenciais-paulistanos-sao-ilegais>. Acesso em: 15 mar. 2012.

SANTA MARIA. Prefeitura Municipal. IPTU: Dúvidas frequentes. [2013]. Disponível em: <http://www.santamaria.rs.gov.br/financas/175-duvidas-frequentes>. Acesso em: 20 maio 2013. 